\title{
CALDERÓN Y LA GUERRA: DEL SITIO DE BREDÁ AL SITIO DE GALERA
}

De una forma u otra, la guerra está presente en muchas comedias de Calderón, aunque pocas veces mostrada directamente en escena, sin duda a causa de su escasa representabilidad dramática. En varias ocasiones, Calderón llevó al escenario una situación bélica que fue de gran importancia en las estrategias militares de su época: el cerco de una población. Una comparación de dos de estas comedias -El sitio de Bredá y Amar después de la muerte- arrojará mucha luz sobre las ideas y actitudes del dramaturgo frente al arte de sitiar y a la guerra en general.

En El sitio de Bredá, el cerco de esta ciudad brabantina -muy célebre por el cuadro que dedicó Velázquez a su rendición finalconstituye el marco en que se inscribe la totalidad de la acción dramática. En la acción de Amar después de la muerte, en cambio, el cerco de la villa granadina de Galera ocupa un lugar mucho más discreto, no produciéndose el cerco hasta la jornada tercera, y siendo conquistada la villa sin problema alguno. Sin embargo, el cerco no deja de tener cierta importancia en la obra, ya que la acción bélica ha sido anunciada de muchos modos y casi incesantemente a lo largo de la jornada segunda, y es el marco en el que tiene lugar la muerte violenta de la joven morisca Clara Malec, que es la acción central de la obra junto con su venganza por parte de su marido, don Álvaro Tuzaní.

Otra diferencia entre las dos obras la marca el hecho de haber sido El sitio de Bredá, casi seguramente, una obra de circunstancias, escrita tal vez por encargo, por lo que el autor puede haberse callado algunas cosas que le hubiera gustado decir. Esto, al menos, podría ser lo que insinúa Calderón en los enigmáticos versos finales:

NRFH, LVI (2008), núm. 1, 31-51 
Y con esto se da fin

al Sitio, donde no puede

mostrarse más quien ha escrito,

obligado a tantas leyes

(vv. 3231-3234)1.

No obstante estas diferencias, el modo de representar el cerco de Bredá ${ }^{2}$ y el cerco de Galera se presta muy bien a una comparación, y precisamente en el contraste veremos "mostrarse más quien ha escrito".

Por supuesto, no hay que confundir la acción dramática de estas dos obras con la acción histórica que pretenden reflejar, y ni siquiera con la versión de los hechos que dan las fuentes escritas de las que derivan más directamente. No obstante, el contraste que pretendo establecer entre las dos comedias no carece de base histórica, por lo que conviene fijarnos primero, aunque sea brevemente, en las fuentes.

La fuente principal de El sitio de Bredá fue sin duda la Obsidio Bredana de Hermann Hugo, publicada en Amberes en 1626. Abarca los sucesos en los Países Bajos, desde la toma de decisiones que condujo al sitio hasta las celebraciones y alabanzas posteriores a la rendición de Bredá. Proporcionó a Calderón varios elementos secundarios de la acción dramática: la estratagema de marchar sobre Grave para luego dar la vuelta hacia Bredá, engañando así a los holandeses y desviando sus esfuerzos defensivos y logísticos hacia Grave, por ejemplo; o la visita al campo de Spínola por parte del príncipe de Polonia (que tal vez proporcionó a Calderón el nombre del protagonista de otra comedia suya: el príncipe Segismundo). La Obsidio Bredana es una exposición de los hechos bastante neutral y parca en comentarios personales o juicios de valor. El autor atribuye uno de los más explícitos al Papa Urbano VIII, en una carta de agosto de 1625: "Irá por todos los siglos la memoria del cerco de Breda, y de ella aprenderán los capitanes de la posteridad las artes de la guerra y los ejemplos de la fortaleza" (p. 181) ${ }^{3}$. Hugo alaba

${ }^{1}$ Cito por la edición de S. A. Vosters (incluida en Het beleg en de overgave van Breda III, Gemeentearchief, Breda), que resulta ser la más fiable de las que he consultado.

${ }^{2}$ Acentúo el topónimo de acuerdo con su pronunciación en la comedia, que corresponde a la pronunciación correcta en neerlandés.

${ }^{3}$ Cito aquí y, en adelante, de Hermann Hugo, Sitio de Breda, ed. J. Albi de la Cuesta, Balkan, Madrid, 2001, ed. que al parecer reproduce la traducción española de 1627; modifico ligeramente la puntuación. 
sobre todo la magnanimidad que, a despecho de las opiniones de sus soldados, mostró el Marqués de Espínola en las negociaciones sobre la capitulación de la ciudad:

Muchos inclinados al rigor, oyendo las blandas y favorables condiciones, se maravillaban de la clemencia que usaba el Marqués con los enemigos: algunos le acusaban por remiso, diciendo que se hubiera de proceder más ásperamente, o hacer pasar a los sitiados por debajo de las picas, sin aceptar a los que se entregaban, si no entregasen juntamente las armas, pues con su grandísima pertinacia se habían puesto a tal peligro que perecieran de hambre si quedaran cercados otros dos días. ¿Y para qué se había de ofrecer la elección de partidos honrosos a los que habían de tener por extraordinario beneficio el concederles solamente la vida? Que por lo menos hubiera de aguardar algo el Marqués, hasta que les sucediera lo que suele a los hombres demasiado obstinados, que procuran y piden con la mayor instancia cosas que antes menospreciaron: suplicaran ellos primero por la entrega, no se les ofreciera. ¿Y para qué dejaba salir la parte peor de los vecinos con sus haciendas y muebles, sin que hubiese pagado el magistrado a los católicos que quedaban el dinero que por orden común y pública les sacaron para la fortificación y pagas de la gente? Parecía que así se quejaban con razón los que, acostumbrados a las particulares, quieren medir con el mismo pie las cosas mayores del Imperio; porque no saben que es diferente la suerte de los príncipes, que han de tener en todo la principal cuenta con la fama. Pero el Marqués, entendiendo que saben más los que más blandamente castigan, y que es la opinión de la clemencia mejor que el nombre de la severidad; importando también tanto por los movimientos de Francia, Italia, los de Alemania y Dinamarca, el desembarazar lo más presto que se pudiese las armas del Rey, que tanto se detuvieron en Breda, tenía por mayor ganancia aun el mínimo espacio de tiempo que los despojos no grandes de toda Breda, o alguna ignominia del enemigo, que se había defendido valerosamente, acordándose del adagio antiguo que hay cosas en que más vale recibir daño que provecho; y juzgando asimismo que debía más tener cuenta con la clemencia y majestad de su Rey, cuyas partes hacía en este lugar, que con su propia gloria o venganza (pp. 169-170).

Los artículos de capitulación que recoge Hugo, y que quedarán luego bien reflejados en la comedia de Calderón, confirman este espíritu de generosidad con los vencidos, que dejaba a los moradores de Bredá no sólo con la vida, sino con no pocos derechos y garantías, incluso en materia de religión. 
Frente a este desenlace nada violento del asedio de Bredá en 1625, parece pertenecer a otro mundo la toma de Galera en enero de 1570, uno de los episodios más sangrientos de la rebelión de los moriscos granadinos y su consiguiente represión. El comandante de las tropas reales fue nada menos que don Juan de Austria, hermanastro del rey Felipe II, pero no parece haber habido en su actitud nada de la magnanimidad mostrada más tarde por Espínola en los Países Bajos. Luis de Mármol Carvajal, que aspiró a ser cronista de dicho rey, y al que nadie acusará de querer desprestigiar a la monarquía, anotó la siguiente arenga del joven don Juan a la vista de Galera:

Yo hundiré a Galera y la asolaré y sembraré toda de sal, y por el riguroso filo de la espada pasarán chicos y grandes, cuantos están dentro, por castigo de su pertinacia y en venganza de la sangre que han derramado.

Cumplió su promesa el implacable Austria, como narra Mármol más adelante:

...todos fueron muertos, porque aunque se rendían, no quiso don Juan que diesen vida á ninguno; y todas las calles, casas y plazas estaban llenas de cuerpos de moros muertos, que pasaron de dos mil y cuatrocientos hombres de pelea los que perecieron á cuchillo en este día...; y como algunos soldados, dejando peleando á sus compañeros, saliesen a poner cobro en las moras que habían captivado, mandaba á los escuderos que se las matasen; los cuales mataron más de cuatrocientos mujeres y niños; y no pararan hasta acabarlas á todas, si las quejas de los soldados á quien se quitaba el premio de la vitoria, no le movieran; mas esto fué cuando se entendió que la villa estaba ya por nosotros, y no quiso que se perdonase á varón que pasase de doce años ${ }^{4}$.

Mármol participó en el asedio de Galera. Ginés Pérez de Hita, cuya Guerra de los moriscos fue la fuente principal de Amar después de la muerte, se basó para la parte correspondiente en un escrito ya perdido de un tal Tomás Pérez de Evia, pero aún así, no pudo ocultar el espanto que le inspiró la forma de proceder de las tropas de don Juan:

${ }^{4}$ Luis de Mármol Carvajal, Historia de la rebelión y castigo de los moriscos del Reino de Granada, VIII, 5. Cito por la edición con introd. de A. Galán, Arguval, Málaga, [1991], pp. 219-220. 
Se usó de tanto rigor y severidad con las mugeres y criaturas que me parece se llevó el estrago mucho más allá de lo que permitía la justicia y era propio de la misericordia de la gente española, que siempre se señaló hasta en favor de los bárbaros; no huvo piedad para ninguno, alcançando la muerte no sólo a las mugeres sino también a las criaturas bautizadas; y tamaño rigor se exerció por averlo mandado assí el Señor Don Juan, a fin de que el acerbo castigo sirviese de exemplo a los demás rebeldes que quedavan por las Alpujarras, temiendo mostrase en adelante pertinaces y con arrogancia contra Su Magestad, por cuya causa se echó el vando de que no quedasse con vida en aquel pueblo hombre, muger ni niño ${ }^{5}$.

Si comparamos mentalmente tales evocaciones de la despiadada matanza de Galera con la escena de refinada cortesía que nos dejó Velázquez en representación de la entrega de la llave de Bredá, comprendemos que estamos ante dos formas muy distintas de rematar el asedio de una población. Don Juan de Austria, al parecer, no hubiera suscrito la opinión de Hermann Hugo, antes citada, de que "saben más los que más blandamente castigan”. Sería tal vez apresurado condenar por ello sin más su forma de proceder. Hay fuertes indicios de que la severidad practicada en Galera tuviera el efecto deseado de romper la voluntad de los moriscos de prolongar su rebelión, en un momento en que se percibía el peligro real de que se extendiera a otras regiones y recibiera un apoyo más decidido de los turcos y del rey de Argel. No le faltarían argumentos al historiador que quisiese defender la dureza de don Juan en Galera como un método exitoso de evitar un mal mayor: son cuestiones que piden, más que una condena apresurada, una ponderación serena, teniendo en cuenta toda la complejidad del momento histórico en que tuvo lugar. De todos modos, lo que nos interesa aquí no es tanto lo históricamente sucedido, sino lo que hizo con ello Calderón. Pasemos, pues, a la consideración de la representación dramática del sitio de Bredá y del sitio de Galera.

Cuando en el teatro barroco español se representan sucesos históricos, la fidelidad a los hechos suele ser, grosso modo, inversamente proporcional a la distancia histórica y geográfica. En obras como La gran Cenobia, Darlo todo y no dar nada, Los cabellos de Absalón, El mayor monstruo del mundo, etc., situadas lejos

5 Ginés Pérez de Hita, La guerra de los moriscos. (Segunda parte de las Guerras civiles de Granada), ed. P. Blanchard-Demouge, est. prelim. e índices J. Gil Sanjuán, Universidad, Granada, 1998, p. 265. 
de España y en tiempos remotos, son a menudo garrafales los anacronismos y audaces las modificaciones del espacio real. En El sitio de Bredá, en cambio, Calderón llevaba al escenario hechos sucedidos hacía tan sólo unos tres años ${ }^{6}$ y en los dominios del rey de España, si bien lejos de la corte. Cierto que esto no le impidió modificar fechas y hechos, pero los conocimientos relativamente precisos que sin duda tenía su público de los sucesos representados le obligó a guardar una fidelidad histórica bastante mayor que en las obras mencionadas.

La distancia histórica era superior en el caso de Amar después de la muerte, y aunque la distancia geográfica era menor, parece que Granada se percibía lo suficientemente lejos de Madrid como para permitir a Calderón adaptar la topografía a sus necesidades artísticas, por ejemplo, situando la villa de Galera en la Alpujarra, muy lejos de su ubicación real. La fecha de Amar después de la muerte es insegura, ya que la datación habitual "hacia 1633" carece de base, y la primera referencia documental a la obra de la que tenemos constancia, de 1659, no parece referirse al estreno ${ }^{7}$. Lo cierto es que, aun en el caso poco probable de que se trate de una obra de juventud, habría pasado más de medio siglo desde la matanza de Galera hasta la redacción de Amar después de la muerte. Con todo, la obra no nos lleva a la Babilonia de Semíramis ni a la Palmira de Cenobia, sino a la España de Felipe II, abuelo del monarca reinante. Calderón pudo modificar los hechos, pero dentro de ciertos límites, un poco menos estrechos éstos que los que imponía El sitio de Bredá.

Por otra parte, Calderón era consciente de la diferencia fundamental entre historiografía y arte literario que resumió sentenciosamente Aristóteles: "la poesía [es] más filosófica que la historia, pues la poesía narra más bien lo general, mientras la historia, lo particular"8. A pesar de basarse en sucesos históricos

${ }^{6}$ Simon A. Vosters, "Again the first performance of El sitio de Bredâ", separata de la RCEH, 6 (1981-82), 117-134.

7 Véase Erik Coenen, "Juan de Vera Tassis, editor de Calderón: el caso de Amar después de la muerte”, RFE, 86 (2006), núm. 2, p. 5.

8 Poética, VIII (cito por la trad. de A. Villar Lecumberri, Alianza, Madrid, 2004, p. 56). El teatro barroco era mucho más aristotélico -que no es lo mismo que neoclasicista- de lo que se ha afirmado desde hace siglos. Véanse, Duncan MoIr, "The classical tradition in Spanish dramatic theory and practice in the 17th century", Classical drama and its influence: Essays presented to $H$. D. F. Kitto, ed. M. J. Anderson, Methuen, London, 1965, y Erik Coenen, "Un eco de la Poética de Aristóteles en La vida es sueño", Estudios Clásicos, 2007, núm. $131,105-126$. 
más o menos conocidos y relativamente cercanos, lo que se propuso Calderón no fue tanto representarlos como aprovecharse de ellos para abordar temas más generales. Amar después de la muerte trata sólo aparentemente de la rebelión de los moriscos; en realidad, sus temas son el amor, el valor, el honor y la infamia. El sitio de Bredá habla de "sitios" en general; es, por así decirlo, un Arte de sitiar. Del mismo modo, cuando se elogia en dicha comedia la valentía de los españoles, no es que Calderón quiera decir que los españoles fueron los más valientes en Flandes; quiere decir que deberán aspirar a serlo siempre. En este sentido, toda la acción de El sitio de Bredá es ejemplar. Desde la escena inicial de la obra, sabemos que asistimos a una acción heroica contra los herejes holandeses, acción que dará "alabanzas al cielo, honor a España" (v. 40). Lo anuncia el "gracioso" Alonso Ladrón ya en el primer verso: "Hoy es, señor, el venturoso día...".

Es interesante contrastar las palabras que acabo de citar con las que, en Amar después de la muerte, emplea don Juan de Austria para anunciar la represión de la rebelión de los moriscos, ya que la retórica usada es idéntica, pero de signo opuesto: "Hoy es, hoy es el día / fatal..." (vv. 887-888) ${ }^{9}$. Frente al "venturoso día” en Bredá, el "día fatal" de Galera. Un día vergonzoso, cuyo responsable histórico había sido don Juan de Austria, y era esta responsabilidad precisamente uno de los hechos que no pudo modificar Calderón, por ser demasiado conocido para sus espectadores. Resulta probable, además, que entre éstos se encontrara como destinatario principal de la obra un hombre de la sangre de don Juan, el rey Felipe IV, por lo que Calderón tuvo que enfrentarse con el problema de cómo representar a don Juan de Austria en un momento tan poco glorioso de su carrera militar. Esto explica tal vez el anacronismo más notable de la obra: representar a don Juan como el triunfador de Lepanto cuando en realidad todavía no lo era ("Tú que fuiste en Lepanto / caudillo de la fe, del turco espanto, / y cristiano Neptuno", wv. 907-908). De este modo, la nada gloriosa conquista de Galera se ve eclipsada por la gloriosísima victoria en el mar, que no llegaría a producirse históricamente sino hasta $1571^{10}$.

${ }^{9}$ En adelante cito por mi edición de la obra, de próxima aparición, Cátedra, Madrid, 2008.

${ }^{10} \mathrm{El}$ procedimiento seguido por CALDERón para atenuar la mala imagen que podría quedar de don Juan en la obra recuerda una escena espléndida de Darlo todo y no dar nada, en la que Calderón aconsejó el método adecuado para representar artísticamente los defectos de los poderosos. A tres pintores 
El asunto central de Amar después de la muerte -la venganza del infame asesinato de Clara Malec en la toma de Galera -no permitía a Calderón ocultar la índole sangrienta de lo históricamente ocurrido, que además era de sobra conocido. De ahí que Calderón haga a don Juan aparecer en escena poseído no sólo de la ira que le atribuyó Mármol Carvajal, sino también de cierta vergüenza ante una misión consistente no en alcanzar glorias militares sino en "castigar" lo que tilda de "alevosía". Sabe el joven Austria que el escarmiento que se pretende dar a los moriscos merecerá "poco aplauso" de la "fama",

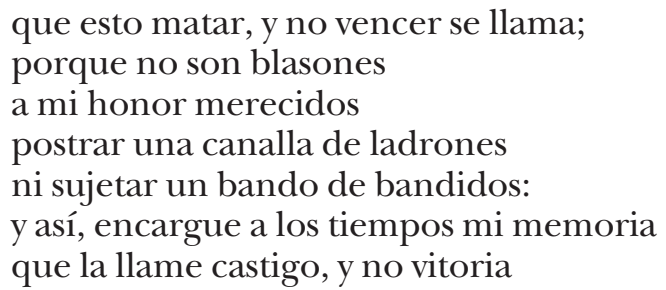

La gloria y la fama futuras -aspiraciones máximas en el sistema de valores clásico y renacentista -que no merecerá la acción bélica de Amar después de la muerte, las ganará en abundancia la del Sitio de Bredá. El cerco a la ciudad brabantina es tan perfecto que ésta se ve aislada del mundo exterior, sin poder recibir ni víveres ni apoyo militar. Bredá acaba no teniendo más remedio que rendirse sin librar batalla, conforme a los hechos históricos. Es precisamente esta evitación de la violencia lo que se presenta como lo más "glorioso" del cerco de Bredá. De este modo lo explica don Luis de Velasco en la jornada primera:

les ha sido encargado retratar a Alejandro Magno. Timantes ha hecho un retrato halagüeño, corrigiendo el ojo bizco que en la comedia se atribuye al conquistador, y éste rechaza su retrato por lisonjero. Zeuxis, en cambio, ha pintado despiadadamente el defecto de su rostro, y ve desechado su cuadro por ofensivo. Apeles ha dado con la solución, retratándole a medio perfil, por lo que el ojo bizco está a la sombra. Alejandro alaba su discreción, y la pone como "político ejemplo / de que ha de buscarse modo / de hablar a un Rey con tal tiento, / que ni disuena la voz, / ni lisonjee el silencio" (cito por las Obras completas, ed. A. Valbuena Briones, Aguilar, Madrid, 1987, t. 2, p. 1028). De modo análogo, Calderón pone la infamia de Galera a la "sombra" de la gloria de Lepanto. 
la gloria

es más prudente y modesta

y más noble cuando cuesta

menos sangre la victoria

(vv. 281-284).

Fijémonos en los adjetivos: conquistar la ciudad sin verter sangre es la manera más prudente-es decir, más sabia-, la manera más modesta-aquí lo opuesto de "soberbia" -y la manera más noble de conquistarla. Noble, en el sistema de valores que maneja Calderón, es casi sinónimo de "moral": lo noble es lo ejemplar, lo excelente, la cifra de todo lo admirable y lo aconsejable.

No es casual que figure en la primera jornada de Amar después de la muerte un comentario similar al que acabo de citar de $E l$ sitio de Bredá, aunque no pronunciado en una situación de guerra, sino en un debate entre nobles sobre la satisfacción de una afrenta: "vence más / aquel que sin sangre vence" (vv. 794-795). Más significativos aún son los versos en los que el protagonista de la obra, don Álvaro Tuzaní, en su llanto por su esposa muerta, trasciende momentáneamente el motivo particular de su dolor para condenar el modo de conquistar Galera. Los términos son diametralmente opuestos a los que empleó Calderón al hablar de la conquista de Bredá. Si Bredá fue teatro de la "gloria más noble", la sierra granadina es

teatro

de la hazaña más cobarde, de la victoria más torpe, de la gloria más infame (vv. 2274-2277).

Calderón, que según el dudoso testimonio de Juan de Vera Tassis participó en la Guerra de Flandes, y que indudablemente participó en la campaña de Cataluña de 1640, sabía valorar las virtudes militares, la disciplina, el valor, el heroísmo, claro está; pero no glorificó la guerra per se. La oposición entre la "gloria más noble", que es la de Bredá, y la "gloria más infame", en Galera, lo corrobora. Comprendía lo que comprende cualquier hombre decente: que la guerra es un mal, quizás ineludible a veces, pero siempre un mal. Es importante cultivar el valor heroico y la destreza en el uso de las armas -vis pacis para bellum, "si quieres paz, prepárate para la guerra”-, pero es siempre preferible evitar el derramamiento de sangre. 
En el modelo social tradicional, heredado de la Edad Media, los nobles tenían la guerra por obligación. Dicho en el román paladino de don Juan Manuel en el Libro de los estados, al lado de los "oradores" y "labradores", ellos eran los "defensores", que podían ver premiadas sus hazañas bélicas con nuevos títulos, encomiendas u otros favores reales. A los soldados rasos y aventureros había que recompensarlos de otro modo, pagándoles, lo cual no siempre era posible, ya que en la época de los Austrias las arcas de la monarquía mostraban una preocupante tendencia a estar vacías. Además, el armamento era cada vez más costoso: con la introducción de las armas de fuego, se había iniciado la secular carrera armamentística que ha seguido su curso hasta el día de hoy, devorando cuantías cada vez mayores de recursos económicos. En tales circunstancias, el saqueo parece haber sido considerado un mal menor frente al riesgo real de un motín incontrolable (como la "furia española" que se desató en Amberes en 1576). El Espínola de El sitio de Bredá es consciente de este riesgo:

$$
\begin{aligned}
& \text { Si no están entretenidos } \\
& \text { los soldados en algunos } \\
& \text { de los sitios que se ofrecen } \\
& \text { para victorioso asunto } \\
& \text { de nuestras armas, podrán } \\
& \text { amotinarse; y no dudo } \\
& \text { que la esperanza del saco } \\
& \text { pueda sufrir con más gusto } \\
& \text { el grave peso a las armas } \\
& \text { (vv. 207-215). }
\end{aligned}
$$

La "esperanza del saco" a la que se refiere Espínola es un tema recurrente en El sitio de Bredá. En la última jornada, con la ciudad dispuesta a rendirse "a partido" (es decir, firmando las capitulaciones pertinentes, que garantizan un trato digno a los habitantes de la ciudad), los soldados de las diversas "naciones" se oponen a esta solución pacífica y parecen a punto de amotinarse. Los soldados alemanes, borgoñeses, escoceses e ingleses ponen el grito en el cielo, reclamando su botín de guerra, como hacen también los valones:

Cuando esperan

los soldados aliviar

los trabajos padecidos 
con el saco entretenidos, ¿quieres se vengan a dar para librarse?

(vv. 2764-2768).

Los únicos en aceptar el trato sin rechistar son los tercios españoles, orgullosos de poder servir a su rey entregándole la ciudad, y además, alegres de poder ganarla sin verter sangre,

pues mayor hazaña es que no manche en tal gloria con la sangre la victoria, y sea Bredá de España.

$$
\text { (vv. 2805-2809). }
$$

Por supuesto, como historiadores, debemos tomar con un grano de sal este final, diseñado para reflejar no una realidad, sino un ideal; no para decir que los españoles son como aquí se los representa, sino para decir que les honraría ser así y deberían aspirar a ello; y esa honra reside, entre otras cosas, en la renuncia de la "esperanza del saco".

En la represión de la rebelión de los moriscos, el saqueo de los lugares rebeldes que no se rendían fue explícitamente autorizado por Felipe $\mathrm{II}^{11}$. En la práctica, se saqueaba por doquier, ya que, como señalan todos los testigos, grupos desmandados de soldados cristianos vagaban por la Alpujarra sembrando terror y desvalijando las villas que se habían rendido, impidiendo así una pacificación eficaz. Y es que, estando los famosos tercios españoles por aquellos años entretenidos en los Países Bajos, los improvisados ejércitos de Granada atrajeron hacia sí a "los mayores ladrones del mundo, desolladores y robadores que no llevavan los pensamientos sino en cómo avían de robar y hurtar y saquear los pueblos de los moriscos que estavan sosegados"12.

El botín fue especialmente copioso en Galera. Como apunta Mármol Carvajal: "Hallóse tanta cantidad de trigo y cebada, que bastaba para sustento de un año, y ganaron los capitanes y soldados rico despojo de seda, oro y alfójar, y otras cosas de precio, que aplicaron para sî" (VIII, 5). Esta abundancia queda reflejada

11 Mármol Carvajal, op. cit., VII, 11.

12 Pérez de Hita, op. cit., p. 39. Véase también Mármol Carvajal, op. cit., VI, 1-3. 
en la comedia de Calderón en un diálogo entre don Juan de Austria y don Lope de Figueroa:

\begin{tabular}{cl} 
Don Lope & \multicolumn{1}{c}{$\begin{array}{c}\text { No ha habido } \\
\text { saco jamás que haya dado } \\
\text { más provecho: no hay soldado } \\
\text { que rico no haya venido. } \\
\text { ¿Tanto tesoro escondido } \\
\text { dentro de Galera había? }\end{array}$} \\
Don JuAn & $\begin{array}{l}\text { Dígatelo la alegría } \\
\text { de tus soldados }\end{array}$
\end{tabular}

(v. 2460-2467).

Estos comentarios los hacen dos personajes históricos ilustres por sus hazañas militares, personajes que en un principio no figuran entre los que se aprovechan de los saqueos. Los que se aprovechan son los soldados rasos, que apenas figuran en estas obras. En El sitio de Bredá, se llega a afirmar, de las tropas de la monarquía, que:
No se ha visto en todo el mundo ...unida tanta nobleza; pues puedo decir que no hay un soldado que no sea por la sangre y por las armas noble

$$
\text { (vv. 2175-2182). }
$$

Entre los defensores de Bredá-es decir, entre los "enemigos"-, tampoco encontramos a ningún personaje de baja estofa. Lo mismo ocurre con los "enemigos" en Amar después de la muerte, ya que, con la sola excepción del gracioso Alcuzcuz -figura meramente convencional, como ya demuestra su absurdo nombre-, todos los personajes moriscos de la obra son nobles granadinos, que se retiran a la Alpujarra para liderar la rebelión de un "pueblo" que no aparece por ningún lado. Es por ello difícil de aceptar -dicho sea de paso - una interpretación de la obra según la cual su tema sería "la tragedia del pueblo morisco"13.

13 Antonio Regalado, Calderón. Los orígenes de la modernidad en la España del Siglo de Oro, Destino, Barcelona, 1995, t. 1, p. 836. Una interpretación similar la propone J. M. CAso GonzÁlez, "Calderón y los moriscos de las Alpujarras", en Calderón. Actas del "Congreso internacional sobre Calderón y el tea- 
Sin embargo, en ambas obras hay un soldado raso entre los personajes que representa el ejército de la monarquía. En El sitio de Bredá es Alonso Ladrón -el nombre lo dice todo-, que representa la actitud más vil ante la guerra, aunque bastante suavizada por su carácter de "gracioso" de la obra. En esto último se distingue del soldado raso cristiano que aparece en Amar después de la muerte, Garcés, cuya vileza, apenas matizada por sus modestos arrebatos de arrepentimiento, le señala claramente como el malo de la obra. Alonso Ladrón ansía el saqueo de Bredá y disfruta de ver quemarse a los "herejes" holandeses (vv. 832-838). Garcés anuncia su deseo de entrar en Galera

$$
\begin{aligned}
& \text { sin que pueda con mi rabia, } \\
& \text { sin que valgan con mi acero, } \\
& \text { ni en los niños la piedad, } \\
& \text { ni la clemencia en los viejos, } \\
& \text { ni el respeto en las mujeres }
\end{aligned}
$$

(vv. 1778-1782).

Alonso Ladrón, en El sitio de Bredá, ve defraudadas sus esperanzas de botín. Garcés, en Amar después de la muerte, las satisface plenamente. Entra en Galera como primero, gritando "Ninguna vida hoy se guarde / de mi acero, por hermosa / o por caduca se escape" (vv. 2154-2156), y al entrar en un palacio opulento que promete mucho botín, se encuentra con "la más bella africana / que vieron jamás mis ojos” (vv. 3017-3018), que es Clara Malec, esperando en la cama la llegada de Álvaro para consumar su reciente matrimonio. La llegada de otros soldados no permite a Garcés violar a la joven morisca, por lo que le despoja rápidamente de sus joyas y la mata a puñaladas.

No hay nada fuera de lo común en tales acciones, que son el pan de cada día de las guerras y lo eran mucho más en la época de Calderón. Ya citamos las palabras de Pérez de Hita sobre la proliferación de "robos y hurtos" en la represión de la rebelión de los moriscos. Todos los testimonios hablan también de la frecuente violación de mujeres y de su captura como esclavas. En cuanto a los saqueos, durante la Guerra de los Treinta Años, que coincidió con el período en el que probablemente se escribió Amar después de la muerte, llegaron a ser practicados a gran

tro español del Siglo de Oro (1981)”, ed. L. García Lozano, CSIC, Madrid, 1983, pp. 393-402. 
escala, como única estrategia posible de supervivencia para los innumerables soldados mercenarios ${ }^{14}$.

Para examinar la actitud de Calderón ante este modo de hacer la guerra, conviene analizar más detenidamente varias facetas de Amar después de la muerte, ya que transmite esa actitud no tanto poniendo determinadas afirmaciones en boca de sus personajes como manipulando hábilmente los sentimientos de su público ante la acción que presencia: despertando simpatía y antipatía con sus personajes, contrastando sus comportamientos, persiguiendo efectos patéticos, etc.

Desde la escena inicial, Calderón presenta favorablemente a sus protagonistas moriscos, que acabarán siendo víctimas del despiadado modo de conquistar Galera. Dotarles de una cara, un nombre, una identidad, ya de por sí es una forma de fomentar la empatía del espectador y, con ella, su indignación posterior al presenciar el destino de estos personajes. Uno de los dignatarios más respetados entre los moriscos es el venerable anciano don Juan Malec, Veinticuatro de Granada y padre de Clara Malec, que tiene poco en común con el temerario y despiadado Jerónimo el Maleh histórico, en el que está basado. Malec, que acabará muriendo en escena, en defensa tan valiente como inútil de Galera, irrumpe en el primer cuadro de la obra para dar cuenta de la afrenta que acaba de sufrir a manos de un noble cristiano mucho más joven, don Juan de Mendoza. Esta afrenta será presentada por Calderón como una infamia, teniendo en cuenta la senectud de Malec, que le impide defenderse o vengarse.

Si Calderón dota a don Juan Malec de no pocas virtudes, a su protagonista, don Álvaro Tuzaní (que después de estallada la rebelión pasará a llamarse "el Tuzaní”), lo representa sistemáticamente como un noble modélico e incluso heroico, provisto de las virtudes más ensalzadas en aquel sistema de valores al que Schlegel llamaba "caballeresco": la valentía, la honradez, la generosidad, y por supuesto aquella cualidad imprescindible del verdadero noble, la de estar enamorado, con un amor constante y honrado para una doncella tan digna de tal amor como doña Clara Malec. Calderón insiste, por lo demás, en que la caballerosidad de los nobles moriscos es indistinguible de la de un noble cristiano. En el duelo que acaba produciéndose al final de la jornada primera entre don Álvaro Tuzaní y don Juan de Men-

14 Véase, por ejemplo, Michael Howard, War in European history, Oxford University Press, 1976, p. 37. 
doza, los dos contrarios son indistinguibles en sus actitudes, no profesando cada uno su respectiva "ley" religiosa, sino ambos las mismas "leyes de caballero" (v. 752).

También a Clara Malec (más tarde "Maleca") la retrata Calderón como una noble ejemplar. Es celosa de su honra, y siente el impulso de vengar a su padre cuando éste ha sufrido una afrenta, por lo que lamenta que su condición de mujer no le permita tales acciones (vv. 236-275). Reúne las dos cualidades que Calderón suele atribuir a las mujeres perfectas, que son la hermosura y el ingenio (vv. 248-249 y 492-494) ${ }^{15}$. Su amor -que es la "noble pasión" por excelencia'16 es igual de constante y honrado como el de Tuzaní. La mayor parte de lo mucho que Calderón añadió a la anécdota que extrajo de la Guerra de los moriscos, de Pérez de Hita, consiste en una serie de dificultades con que se enfrentan don Álvaro y doña Clara a lo largo de la primera y segunda jornadas. Es sobre todo don Álvaro quien tendrá que superar estas pruebas para poder ver colmadas sus esperanzas (momento que, sin embargo, no llegará nunca). Primero, ve deshonrado a don Juan Malec, el padre de su amada, y con él a todo su linaje, pero no por ello la abandona, sino que, muy al contrario, procura casarse con ella cuanto antes para poder vengarla. Luego, tiene que sufrir su negativa a casarse con él ("tu mujer no he de ser, / porque no tengas mujer / tú, de un padre sin honor", vv. 293-295) e incluso su aceptación de un matrimonio nada menos que con su adversario, don Juan de Mendoza (vv. 428-567). Su duelo con Mendoza queda inconcluso y tiene como única consecuencia nuevas afrentas a su amada Clara. Ya en la jornada segunda se casa por fin con ella, pero no tiene la oportunidad de consumar el matrimonio a causa de la llegada de las tropas cristianas a la zona. Un encuentro nocturno y furtivo con ella es interrumpido de nuevo por las cajas del ejército cristiano, y el intento de fuga de los dos se ve frustrado.

Así, al arrancar la última jornada -en la que será tomada Galera, asesinada y despojada Maleca, y finalmente vengada su muerte- han sido puestos a prueba una y otra vez el amor y el honor de don Álvaro, y la heroica ejemplaridad con la que supera todas estas pruebas no puede sino haberle ganado la simpatía

\footnotetext{
${ }^{15}$ Compárese, por ejemplo, la descripción de Serafina en El pintor de su deshonra: "Es su hermosura divina / y es su ingenio singular" (ed. A. Valbuena Briones, Espasa-Calpe, Madrid, 1978, vv. 84-85).

16 Así lo hace llamar Calderón en la escena inicial de No hay burlas con el amor.
} 
del público. La acumulación de malos agüeros hacen temer por el fin que le espera, y la frustración de sus repetidos intentos de consumar su amor, de gozar carnalmente de quien lleva años sirviendo, contribuye al desgarrador patetismo de la escena en la que se encuentra finalmente con su esposa moribunda entre las ruinas de Galera y dirige a sí mismo o al público la pregunta:

¿qué debe hacer un amante que viniendo a ver su dama la noche que ha de lograrse un amor de tantos días, bañada la halla en su sangre? (vv. 2253-2257).

Que Clara haya sido muerta precisamente en "la noche que ha de lograrse / un amor de tantos días" incrementa la emotividad de este planctus, y también (podemos suponer) la compasión del espectador, a la par que su repugnancia ante las acciones de Garcés. El efecto se intensificará en la escena culminante de la obra, que es acaso una de las escenas de mayor fuerza dramática del teatro universal. Estando presos don Álvaro y Garcés, éste relata por extenso su asesinato de Clara, mientras aquél consigue a duras penas disimular y suprimir la furia que hierve en sus entrañas. La escena posee una espléndida ironía dramática, ya que Garcés cree estar ante un soldado cristiano e ignora por completo que el hombre a quien dirige el relato de sus fechorías es el marido de la víctima. Para el público, en cambio, que ha tenido plena oportunidad de identificarse y simpatizar con don Álvaro, le resultará fácil imaginarse los violentos sentimientos de don Álvaro cuando el malhechor recuerda cómo encontró a Clara:

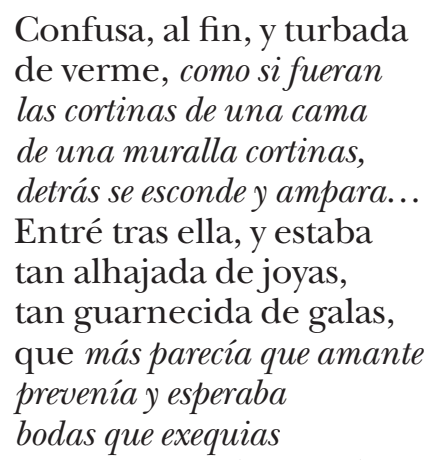

(vv. 3021-3040). 
Todo esto no puede sino incrementar la indignación del espectador ante las mezquinas acciones de Garcés. El público tiene además otras razones para sentir tal indignación. Una muy importante se plasma en las joyas a las que se refiere Garcés ("tan alhajada de joyas"). Éstas, que incitaron su codicia, las ha visto el público ya varias veces: son las mismas joyas que el Tuzaní regaló a Maleca en sus bodas, en prenda de su amor, pronunciando unos versos de exquisita delicadeza. Para el espectador que oye a Garcés relatar su robo, es imposible no recordar esa escena de la jornada segunda, una escena de gran ternura pero sembrada de malos agüeros. Lo que ha robado Garcés no son simplemente las joyas de Maleca: son el símbolo del inquebrantable lazo amoroso que une al Tuzaní y Maleca.

Antes de cruzarse con Garcés, y antes incluso de conocer la identidad del responsable de la muerte de Maleca, el Tuzaní, en su búsqueda de venganza, se infiltra en el campo cristiano con la esperanza de descubrir al culpable. Es entonces cuando reaparecen las joyas. El Tuzaní ve desde una discreta distancia nada menos que a don Juan de Austria y don Lope de Figueroa comentando las riquezas que se han saqueado en Galera y admirando una sarta de perlas que don Lope ha comprado a Garcés y que el espectador no puede sino reconocer. A continuación, ve a unos soldados que han jugado y apostado otro de los obsequios del Tuzaní, un Cupido de diamantes tan reluciente como simbólico. Estas escenas de los soldados vencedores manoseando las joyas de sus adversarios más nobles, parecen haber sido calculadas para conseguir un efecto máximo de repulsa e indignación en el público, y dicen mucho más sobre cómo veía Calderón la costumbre del saqueo que ninguna afirmación explícita de sus personajes.

No es que falten tales afirmaciones. Al contrario, más de una vez Calderón pone en boca de sus personajes comentarios que no pueden sino subrayar el manifiesto significado de las escenas que acabamos de comentar. El propio Garcés, que parece sentir algún remordimiento por sus actos, acaba deslizando una observación al respecto en su relación de lo sucedido: "entre el aplauso buscaba / el provecho, aunque mal juntos / provecho y honor se hallan" (vv. 3009-3011). Anteriormente, disculpándose por otras acciones suyas indebidas pero bastante más fáciles de perdonar, Garcés aduce en términos más generales "que aun la ambición del honor / no es ambición de provecho" (vv. 1731-1732). En otro momento de la obra, Maleca, en sus últimas palabras antes 
de expirar en brazos del Tuzaní, describe a su asesino como "un español, / de sus joyas y diamantes / más que de honor ambicioso" (vv. 2219-2220). Desde luego, tal insistencia en la oposición entre la "ambición de honor" y la "ambición de provecho" no es fortuita 17 .

La misma oposición se insinúa en las palabras de don Álvaro cuando, al ver la sarta de perlas en manos de don Juan de Austria, no puede creer que sea éste el culpable de la fechoría:

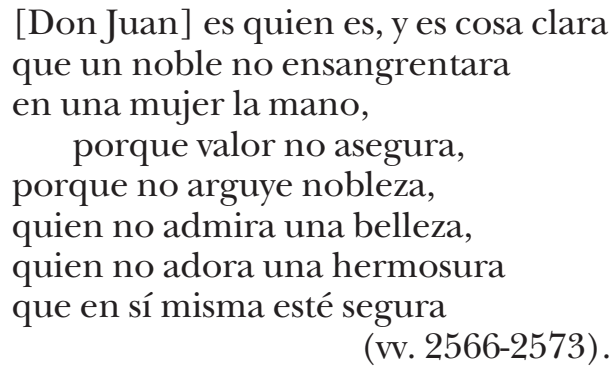

De nuevo aparece aquí la noción de nobleza, como condición social pero también como ideal ético. Don Juan de Austria, hijo de Carlos V, hermanastro del rey, y por tanto hombre de altísimo nacimiento, no puede ser el culpable, porque noblesse oblige: la verdadera nobleza respeta a las mujeres y ambiciona el honor, que no el provecho. De ahí que el mero pensamiento de que haya sido él quien mató y despojó de sus joyas a Maleca es una infamia.

Encontramos una idea análoga en El sitio de Bredá, en una acción que en cierto sentido es la opuesta de la cometida en Amar después de la muerte que acabamos de comentar. En la jornada primera, las tropas bajo el mando de Espínola fingen marchar sobre Grave, desviando a las tropas holandesas hacia esa ciudad, para luego dar la vuelta y dirigirse a Bredá. La bella holandesa, madame Flora, que por estas noticias ha huido de Grave con su padre anciano y un hijo pequeño, es sorprendida antes de llegar

17 Compárense, en El segundo Escipión-otra comedia dedicada en gran parte al sitio de una ciudad-, lo expresado en los juegos de palabras del gracioso Turpín, quien, al prever que las 'piedades' de Escipión le harán parar la matanza y el saqueo de Carthago Nova, se apresura a entrar en la urbe: "por si manda Escipión / que cese el saco, no pueda / por mí decir el proverbio / que honra y provecho en un saco / no caben. De honra y provecho, / que del saco he de sacar / llena la bujaca pienso" (en Obras completas, ed. cit., t. 2, p. 1441). 
a Bredá por el capitán español don Fadrique, que "sale con la espada desnuda”, como dice la acotación. Arrojándose a sus pies, madame Flora implora su misericordia:
A tus plantas, español generoso (que la gala tuya lo dice, y el brío no lo desmiente), a tus plantas está pidiendo la vida una mujer desdichada; aunque, si eres español, mujer que te diga basta. No permitas que ese acero, cuya cuchilla templada está en la enemiga sangre, que ya le sirve de vaina, se ocupe en tres inocentes vidas, porque, ¿qué alabanzas dará manchar este cuello, estas tocas, estas canas?

(vv. 729-744).

Lo mismo que en las palabras antes citadas del Tuzaní, aparece aquí la idea de que un noble que se precie de serlo -es decir, un español como deben ser los españoles- "no ensangrentara en una mujer la mano". La aspiración a la fama -aquí, a las "alabanzas” posteriores -lo prohíbe. Prosigue madame Flora:

Tres vidas están sujetas a un golpe: si acaso alcanza el orden que traes licencia a una piedad tan hidalga, danos la vida. Yo quise decirte (estaba turbada) que a precio de algunas joyas, piedras, perlas, oro y plata; mas tu piadoso semblante puso freno a mis palabras, y a tanto respeto obliga esa presencia bizarra, que aun creo que el pensamiento, con ser tan veloz te agravia

(vv. 745-758). 
Al noble le corresponde mostrar una "piedad hidalga"; y del mismo modo como para don Álvaro Tuzaní habría sido ya una afrenta pensar que don Juan de Austria hubiera despojado a Maleca de sus joyas, madame Flora sospecha que don Fadrique se sentirá ofendido si se le ofrecen "joyas, / piedras, perlas, oro y plata”.

Late en el fondo de esta escena la misma oposición que se establece en Amar después de la muerte entre la "ambición de honor", propia del noble, y la "ambición de provecho" propia de seres ruines como Garcés. A éste, Maleca sí le ofrece joyas, y huelga decir que no se ofende. Lo recuerda así el propio Garcés cuando narra sus fechorías al Tuzaní:

$$
\begin{aligned}
& \text { Apenas, pues, me atreví } \\
& \text { a asirla una mano blanca, } \\
& \text { cuando me dijo: -Cristiano, } \\
& \text { si es más ambición que fama } \\
& \text { mi muerte, pues con la sangre } \\
& \text { de una mujer más se mancha } \\
& \text { que se acicala el acero, } \\
& \text { estas joyas satisfagan } \\
& \text { tu hidrópica sed, y deja } \\
& \text { limpio el lecho } \\
& \text { (vv. 3044-3053). }
\end{aligned}
$$

Garcés se lleva las joyas de Maleca, pero no deja "limpio el lecho", empapándolo de la sangre de la joven. En la escena citada de El sitio de Bredá, en cambio, don Fadrique no sólo deja con vida a madame Flora con su padre e hijo, sino que les ofrece dos caballos:

Aquesas riquezas guarda; y porque de otros soldados, madama, segura vayas, dos caballos he traído. Huid los dos, y a las ancas del uno irás tú: españoles son, no temas

(vv. 790-796).

A lo que contesta Flora: "No me espantan; / que pienso que cortesía / saben los brutos de España” (vv. 796-798). El fin de toda esta idealización de la cortesía y caballerosidad españolas 
no es, insisto, halagar la vanidad del público, sino ofrecerle un modelo de excelencia. Frente a este modelo, Garcés, que demuestra saber menos "cortesía" que la atribuida a "los brutos de España”, es un modelo negativo, un modelo de vileza, un ejemplo a no seguir.

Concluyendo, Calderón, en El sitio de Bredá y en algunas partes de Amar después de la muerte, despliega sendos modelos, radicalmente opuestos, del arte de sitiar y de la guerra en general. En el primero ofrece -junto a la exaltación de los valores militares tradicionales como la valentía y el afán de gloria heroica- una glorificación de las tácticas militares que reducen al mínimo la violencia, mientras que en el segundo ejemplifica, en el asesinato de Clara Malec -tan infame como innecesario en términos militares-, su rechazo al rigor excesivo. En el primero alaba sobre todo la ausencia del pillaje en la ciudad y el trato respetuoso y generoso para con el vencido, mientras que en el segundo, por medio de una especie de exemplum negativo, transmite su rechazo a lo contrario: el saqueo y la humillación de los vencidos. Como don Juan Manuel, como el Canciller Ayala, como el Marqués de Santillana, como Antonio de Guevara, como Gracián, como Saavedra Fajardo, en fin, como tantos autores de los siglos medievales y áureos, Calderón fue un educador de nobles y príncipes, y una de las cosas más importantes que tenían que aprender era cómo hacer la guerra. No desaprovechó Calderón la oportunidad que le brindaban algunos de sus argumentos para dar lecciones al respecto.

ERIK COENEN

Universidad de Alcalá 